\title{
Dentin hypersensitivity: pain mechanisms and aetiology of exposed cervical dentin
}

\author{
N. X. West • A. Lussi • J. Seong • E. Hellwig
}

Received: 19 April 2012 /Accepted: 21 November 2012 /Published online: 9 December 2012

(C) Springer-Verlag Berlin Heidelberg 2012

\begin{abstract}
Objectives The paper's aim is to review dentin hypersensitivity (DHS), discussing pain mechanisms and aetiology. Materials and methods Literature was reviewed using search engines with MESH terms, DH pain mechanisms and aetiology (including abrasion, erosion and periodontal disease).

Results The many hypotheses proposed for DHS attest to our lack of knowledge in understanding neurophysiologic mechanisms, the most widely accepted being the hydrodynamic theory. Dentin tubules must be patent from the oral environment to the pulp. Dentin exposure, usually at the cervical margin, is due to a variety of processes involving gingival recession or loss of enamel, predisposing factors being periodontal disease and treatment, limited alveolar bone, thin biotype, erosion and abrasion.

Conclusions The current pain mechanism of DHS is thought to be the hydrodynamic theory. The initiation and progression of DHS are influenced by characteristics of the teeth and periodontium as well as the oral environment and external influences. Risk factors are numerous often acting synergistically and always influenced by individual susceptibility.
\end{abstract}

\section{N. X. West $(\bowtie) \cdot J$. Seong}

Clinical Trials Unit, Department of Oral and Dental Sciences, Bristol Dental Hospital, Lower Maudlin Street,

Bristol BS1 2LY, UK

e-mail: n.x.west@bristol.ac.uk

\section{A. Lussi}

Department of Operative Dentistry, Preventive and Pediatric

Dentistry, School of Dental Medicine, University of Bern,

Bern, Switzerland

\section{E. Hellwig}

Department of Operative Dentistry and Periodontology,

Dental School and Hospital Dentistry,

University Medical Center Freiburg,

Freiburg im Breisgau, Germany
Clinical relevance Whilst the pain mechanism of DHS is not well understood, clinicians need to be mindful of the aetiology and risk factors in order to manage patients' pain and expectations and prevent further dentin exposure with subsequent sensitivity.

Keywords Dentin hypersensitivity (DHS) - Gingival recession $\cdot$ Non-caries cervical lesions $(\mathrm{NCCL}) \cdot$ Abrasion . Erosion $\cdot$ Abfraction

\section{Introduction}

The first part of this paper will focus on pain mechanisms of dentin hypersensitivity, suggesting hypotheses in explanation. Human dentin tubules taper from a diameter of about $2 \mu \mathrm{m}$ at their pulpal end to about $0.5 \mu \mathrm{m}$ or less peripherally and dependent on age of the individual [1-3]. It is also well known that the pulp is richly innervated with sensory afferents, mostly involved in pain mediation [4-6] and that the dentin has limited innervation, yet appears highly sensitive with patency of the dentin tubules [7]. What is less well known, however, is whether the movement of the tubule contents excites the nerve endings directly, either in the inner ends of the tubules or in the superficial pulp, or whether the odontoblasts play a role in the transduction mechanism [7].

The second part of this paper will review the aetiology and risk factors associated with dentin hypersensitivity. The incidence of the condition is thought to be rising year on year due to increased longevity of life accompanied by retention of teeth and maintenance of a healthy dentition $[8,9]$. Dentin must be exposed for pain to exist and dentin tubules patent. The area of dentin thus needs to be localised and the condition initiated by opening the tubules [10]. Individuals suffering periodontal disease frequently have 
exposed radicular dentin as do the healthy individuals from for example overzealous toothbrushing and trauma to the gingival marginal tissues, with subsequent wear of dentin. Hard tissue wear processes of the coronal tooth area are also frequently seen clinically at the cervical margin [10]. Recent changes in lifestyle, notably diet, have been shown to promote dental hard tissue loss by erosion, exacerbating the condition. Both exposed coronal and radicular dentin can be sensitive, but in the majority of cases, this condition preferentially occurs in the buccal, cervical region of the tooth or in the coronal radicular area [11].

\section{Pain mechanisms}

Although much has been learnt about dentin hypersensitivity since it was first documented by Blum [12], clinical evidence-based research, particularly in respect of the pain mechanisms, is lacking and not well understood. Dentin hypersensitivity has been defined as the pain arising from exposed dentin, typically in response to chemical, thermal, tactile or osmotic stimuli that cannot be explained as arising from any other form of dental defect or pathology [13]. Tooth hypersensitivity can fit the criteria of several pain terms as described by Merskey [14] for the International Association for the Study of Pain. Pain being described as an unpleasant sensory emotional experience, associated with actual or potential tissue damage or described in terms of such damage. Perception of pain emanating from the oral cavity is also perceived as disproportionately large regarding the actual physical cause, compared with the rest of the body [15]. The pain of dentin hypersensitivity is classically, short, sharp, of rapid onset in character and of the duration of the applied suitability [16]. The question of how an appropriate stimulus applied to exposed dentin could evoke an essentially instantaneous painful response has been the subject of debate for many decades.

There has been much discussion concerning the pulpal changes, if any, associated with sensitivity pain. Much of the current opinion on dentin hypersensitivity is based on logical and sensible supposition rather than scientific evidence [10]. The status of the pulp in dentin hypersensitivity is not known, although symptoms would suggest it unlikely that there is an acute or chronic inflammation due to the length of time symptoms persist. Most investigations report no correlation between pathology and symptoms [17, 18]; however, studies are fraught with difficulty due to ethical consideration. At a clinical level, even with magnification, sensitive dentin looks the same as non-sensitive dentin. There is little to indicate that hypersensitive dentin differs in any way from normal dentin and the pain mechanisms are probably the same [13]. The term "dentin hypersensitivity" can be questioned, with perhaps "dentin sensitivity" being a more accurate description. However, historically, dentin hypersensitivity has been a useful term as it has described a distinct clinical entity familiar to the dental profession [13]. Some individuals also experience a vague dull, throbbing ache, persisting for variable periods of time after the stimulus has been removed [19]. Whilst this pain sensation could be part of the condition, it does not fit the definition, utilises $\mathrm{C}$ fibres in the innervation process and is highly likely to be due to pulpal inflammation, needing endodontic or exdontia management [10].

In an attempt to explain dentin hypersensitivity, a number of theories have been put forward. One of the early, and most obvious hypotheses, was that dentin was innervated and therefore nerves were directly triggered by the stimulus. Histological stain techniques later proved not to be totally specific for nerve fibres [19]. Later evidence from electron microscopy revealed that nerve fibres do penetrate the dentinal tubules but only for a very short distance into the inner dentin, and mainly over the pulpal horns [20].

A further theory, termed the odontoblast transducer mechanism by Rapp et al. [21], was suggested primarily because odontoblasts are embryologically of neural crest derived mesenchymal cells. It was suggested that odontoblasts acted as receptor cells mediating changes in the odontoblasts via synaptic junctions with nerves. This could result in the sensation of pain from the nerve endings located in the pulpodentinal border. Direct microscopic techniques, as for the first theory, failed to confirm this concept with observation suggesting odontoblastic processes only extend between one third to one half of the dentinal tubule length, $0.5-1 \mathrm{~mm}$ from the pulpal end [22]. A space occurs between the process and the tubule wall [23], filled with dentinal fluid [24]. The reason for this phenomenon is unknown, but it is possibly involved in the pain mechanism. Further criticism of this theory stems from electrophysiological and histological studies, showing that dentin is still sensitive if irritation-induced odontoblast aspiration and nerve injury have occurred [25]. Tooth cavity preparation would destroy or disrupt the odontoblast layer and yet pain will still emanate without a local anaesthetic. Odontoblasts, however, may have a sensory function, with or without metabolic support of nerve fibres or transmission of mechanical disturbances; however, at the time, excitability was not demonstrated by intracellular electrophysiological techniques [26].

Currently, the most widely accepted theory is the hydrodynamic theory. In the nineteenth century, Gysi [27] determined that there was an outward flow of fluid along the dentinal tubules, and proposed, without research evidence, the hypothesis that appropriate stimuli applied to the dentin surface increased change of fluid flow which, in turn, triggered the pulpal nerves. Many years later, Brännström and 
his co-workers published over 20 years worth of studies on both human and animal models [28-30], supporting the theory which has remained the most popular explanation to date. The theory states that sensitive dentin is based on the stimulus-induced fluid flow in the dentinal tubules and consequent nociceptor activation in the pulp/dentin border area [6]. Intradental myelinated A- $\beta$ and some A- $\delta$ fibres are thought to respond to stimuli that displace the fluid in the dentinal tubules resulting in the characteristic short, sharp pain of dentin hypersensitivity [7]. This type of fluid movement can be quantified by measuring the hydraulic conductance of dentin [31]. Thus, dentin with a high conductance has a low resistance, and vice versa. Human studies showed that the patency of the dentinal tubules is an important characteristic of sensitive dentin [6], with a significantly positive correlation between the density of tubules and the pain responses induced from exposed cervical dentin surfaces [32]. Further studies of extracted teeth provided compelling evidence for this requirement with sensitive teeth having many more (eight times) and wider (two times) tubules at the buccal cervical area compared to nonsensitive teeth [33]. Additionally, dye penetration to the pulp was only seen in sensitive teeth [34]. Although number and radius of tubules are relevant to fluid flow and therefore sensitivity, tubule radius is probably more important as fluid flow is proportional to the fourth power of the radius [35] hence if the diameter is doubled, the tubule fluid flow increases by 16 -fold. This explains the concept of why tubular occlusion, of whatever nature, is thought to reduce the pain of dentin hypersensitivity. These features of dentin hypersensitivity lesions clearly have important implications with respect to the possible aetiological factors involved and the development of preventive and management strategies for the condition.

The definition of dentin hypersensitivity highlights a number of stimuli which can evoke a response. Evaporative stimuli such as a triple syringe air jet or cold windy weather results in desiccation of the dentin surface and is thought to increase in the outward flow of fluid in the tubules, as does a cold thermal stimulus and osmotic stimuli such as sugar or acidic fluid [36]. A thermal hot stimulus appears to result in contraction of the fluid in the tubules from in vitro research [37]. Physical stimulation is more difficult to understand, but in theory, compression of the surface such as a "stiletto heel effect" is thought to compress the surface tissue and on release cause expansion and hence increased outward fluid flow [37]. Of all the stimuli, cold is reported as most problematic and is used routinely in clinical trials as a positive stimulus [38]. Alternative interpretations of the hydrodynamic theory have been proposed including the idea that fluid movement may cause an electrical streaming potential $[39,40]$. Whether this can reach proportions to electrically stimulate nerves is not known, but possible.
Recently, new evidence has emerged again promoting the possible major role of the odontoblasts in the dentin sensitivity pain mechanism [41]. The odontoblasts are closely related to the nerve endings, and biological signals are probably transduced from them to the axons and vice versa [41]. Sensory innervation only occurs in dentinal tubules with viable odontoblasts that maintain their columnar form. This relationship, critical for odontoblast behaviour, could be similar to the role that neuregulin and its ErbB receptors play in the control of cell morphology and in hyperalgesia [42]. Much is still unknown, including which proteins mediate signals between the odontoblasts and nerves and whether cilium acts as a signal integrator. Evidence demonstrates odontoblasts express mechano- and/or thermosensitive transient receptor potential ion channels (TRPV1, TRPV2, TRPV3, TRPV4, TRPM3, KCa and TREK-1) [41]. These are likely to sense heat and/or cold or movements of dentinal fluid within tubules. This highlights that the terminal web is a pivotal zone of the pulp/dentin complex for sensing external stimuli. External stimuli causing dentinal fluid movements and or odontoblasts and/or nerve complex responses may represent a unique mechanosensory system with odontoblasts acting as sensor cells in the pain of dentin hypersensitivity [42].

\section{Aetiology and risk factors}

The aetiology of dentin hypersensitivity is based primarily on in vitro and in situ data, case report data and epidemiological surveys, not randomised controlled clinical studies. For dentin hypersensitivity to occur, the dentin surface of a tooth must be exposed (lesion localisation) and a number of dentin tubules in close proximity to each other must be patent from the pulp to the oral environment (lesion initiation) [10]. There is no evidence that there is a differentiation between coronal and radicular dentin hypersensitivity. However, another name for the condition was coined by the 2002 Workshop of the European Federation of Periodontology [43], root sensitivity, without evidence to support a different diagnosis and management strategy. Nevertheless, there are interesting differences in the dentin of crown and root, and throughout its structure. In the crown, the tubules follow a double curved course but in the root and beneath the incisal tips, the tubules take a straighter course [44]. The circumference of the dentin at the peripheral part of the root or crown is much greater then nearer the pulp, leading to the columnar appearance of the odontoblasts as they are squashed together especially over the pulp horns [45]; the convergence of this unique structural organisation estimated at 4:1 [46] or 3:1 [47]. The number of tubules per unit area and radius of the tubules increases from enamel-cemental junction $\left(\sim 20,000\right.$ per $\left.\mathrm{mm}^{2}\right)$ to the pulp $\left(\sim 45,000\right.$ per $\left.\mathrm{mm}^{2}\right)$, 
as does the tubule lumina [48], resulting in the water content or wetness of the dentin increasing 20 -fold from superficial to deep dentin in patent tubules [48]. This may have clinical implications. If the deeper dentin is exposed to the oral environment, it has relatively larger dentinal tubules in closer proximity to each other compared to the original surface dentin structure of the tooth. This has the potential for more rapid tubular orifice fluid flow and sensitivity, greater tubular occlusion necessary to alleviate symptoms. Conversely, the opposite appears to be the case clinical, with small, newly exposed dentin lesions, exhibiting minimal tooth wear at the buccal cervical amelocemental junction, with patent tubules in the region of about $1 \mu \mathrm{m}$ [33], often causing excruciating sensitivity in the young individual [49]. In explanation, the tooth has excellent reparative capability with reactionary and reparative dentin deposition giving rise to considerable heterogeneity in tissue structure from regular to dysplastic atubular structure [50]. The grossly worn dentition rarely being sensitive if occurring over many years, whereas rapid wear in a young adult, is often sensitive, resulting in pain symptoms. The sensitivity of dentin correlates well with tubule patency [6]. The capability and speed of the reparative processes of the tooth and resulting tubule occlusion, as well as age of the pulp, are likely to be very important factors in the susceptibility of an individual to experience the pain of dentin hypersensitivity.

\section{Lesion localisation}

Gingival recession exposing dentin

The most common aetiology of exposing radicular dentin is recession of the gingival marginal tissues. This process is characterised by the displacement of the gingival margin apical to the cement-enamel junction thereby exposing visible cementum of the root surface, which is then rapidly lost [51]. Epidemiologic surveys revealed that gingival recession is a common entity amounting to $60-90 \%$ of the adult Western European population [52]. It is probable that no one factor in isolation leads to the development of gingival recession. Possible causes are thin alveolar cortex, periodontitis and management of the condition, buccal or lingual dehiscence and fenestration of alveolar bone, trauma, orthodontic therapy, oral piercing, self-inflicted injury, prosthodontic treatment traumatising the keratinized gingival and traumatic toothbrushing. These factors could act synchronously [53].

Data are limited, but from reviews [53-55], gingival recession is not age-related. However, it is reported as being positively associated with some patients suffering from horizontal bone loss due to osteoporosis [56]. Gingival recession can also be associated with both healthy and diseased periodontium and high and low standards of oral hygiene [53]. Löe et al. [57] reported that the occurrence of gingival recession was significantly higher in people without any dental hygiene compared to those with a reasonable level of oral hygiene.

There is good evidence demonstrating that periodontal disease and periodontal treatment result in compensatory remodelling of the supporting tissues around the tooth after tissue destruction, leading to an apical shift of the soft tissue margin [58] and often results in root sensitivity, occurring in approximately half of patients following scaling and root planning [59]. The amount of gingival recession that may occur varies with the therapy undertaken [60]. Gingival tissues are rarely static following periodontal treatment and movement can occur over time when patients are in the maintenance phase [61], probably depending on the gingival biotype, underlying bony architecture and remission of stability, as well as harmful patient oral hygiene habits. Recession due to periodontal diseases can be at any site, buccally/ lingually as well as interdentally [62].

Smoking is a risk factor strongly associated with periodontitis and will increase the likelihood of recession in periodontal tissues, depending on the number of cigarettes smoked daily and the duration of the habit [63, 64], being more pronounced in men than in women [63] and particularly after periodontal regenerative surgical procedures $[65,66]$.

What is not so clear is the effect of smoking on the gingival health of people not susceptible to periodontal disease. The research is not conclusive with Gunnsolley et al. [67] demonstrating a strong association between smoking and both attachment loss and recession in subjects who have minimal or no periodontal disease. Other data do not support the hypothesis that smokers not susceptible to periodontal disease are at an increased risk for the development of gingival recession [68]. There is probably a number of confounding factors to explain these differences in the research outcomes, such as the gingival biotype and oral hygiene habits; smokers often brushing their teeth over zealously due to increased staining of the hard tissue [69].

The aetiology of gingival recession in the healthy periodontium is circumstantial and based on clinical observation with epidemiological data [70, 71]. These data associate recession with tooth surfaces that receive the most attention during the brushing cycle [54, 71-74], namely the buccal surfaces. Observing the toothbrushing cycle is far from straight forward due to change in habit on observation. Rugg-Gunn et al. [75] showed the brushing cycle was in the order of about $1 \mathrm{~min}$; however, the tooth surfaces did not receive equal brushing time; the first site receiving the most attention and the last the least $[75,76]$. Recently, there has been an increase in the use of power brushes. Interestingly, their brush head action has not been shown to cause more 
gingival recession than manual brushes documented in a Cochrane Review [77]. Plaque data suggest an inverse relationship with recession; plaque scores lower at recession sites [11]. Epidemiological plaque distribution data show superior plaque control at similar sites to recession, with scores lowest at canine and premolar teeth, buccal surfaces and left sides of the dental arches [78].

During any brushing cycle, the toothbrush is thought to scratch the gingival tissues to some degree [79-81], possibly causing recession. Some individuals are known to be more obsessive regarding toothbrushing habits, particularly those with dentin hypersensitivity, regularly brushing three or more times a day $[82,83]$ and for longer periods of time than the average population [84], again predisposing individuals to more likelihood of permanent trauma and recession. The gingival biotype is rarely mentioned in dentin hypersensitivity studies and reviews, yet places a major role in gingival surgery risk assessment of recession [85-87].

In conclusion, although toothbrushing would appear influential in the trauma to gingival tissues, the benefits of tooth brushing to gingival health, however, far outweigh any downside in respect of resulting gingival recession [88].

Gingival recessions due to other aetiologies have been demonstrated, for example, anatomical predisposition due to absent or thin buccal alveolar bone [89]. Factitious or selfinflicted gingival damage can also cause a problem $[53,55]$. Gingival recession is now not uncommon in young adults with intra- and perioral piercing as they may cause gingival tissue trauma [90, 91]. Sluzkey and Levin [92] found that prevalence, extent and severity of recession correlated with past orthodontic treatment. Frontolateral bruxism has been also associated with the initiation and/or enhancement of the development of gingival recession [93]. A further possible etiological factor may be orthodontic movement of teeth to positions outside the labial or lingual plate, which could lead to dehiscence formation $[56,94]$.

\section{Loss of hard tissue exposing dentin}

Dentin hypersensitivity involves loss of hard tissue exposing dentin. Above the cemental-enamel junction (CEJ), loss of enamel is a necessary prerequisite for dentin exposure, and below the CEJ as soon as cementum is exposed, it becomes non-viable and is lost leaving dentin exposed. While frank carious lesions with dentin exposure of smooth tooth surface are a rather rare finding today, development of non-carious cervical lesions (NCCL) are important factors for dentin exposure at the gingival margin. This process is usually of multifactorial aetiology, and rarely only due to one of the wear phenomenon [95, 96], as demonstrated over many years [97, 98]. Aubry et al. [98] evaluated in a recent study archaeological samples from France and found no NCCLs in 3,927 teeth from 259 individuals. They also reported that the risk of NCCL was higher for women and increased with age. Premolars were the most affected tooth type. The comparison of dental hard tissue microstructure of archaeological and modern teeth has not shown any difference that could explain the different prevalence rates [99]. Non-carious cervical lesions are an entity found in modern civilization produced by nutrition behaviour and the use of tooth cleaning devices [100]. The buccal or labial surfaces of different teeth are the most frequent locations, but lingual and interproximal surfaces may also be affected. While tooth wear is an almost universal condition also in the modern population, severe dentin exposure on cervical sites is relatively uncommon $(2-6 \%)$. The aetiology appears to be multifactorial including abrasion, erosion and possibly microfractures (abfraction) [95, 96]. However, Wood et al. [101] concluded that an abfraction lesion is more likely due to abrasion and erosion only.

Abrasion, the physical wear as a result of mechanical processes involving foreign substances or objects, is a major factor in the aetiology of NCCL [102]. Numerous peer review papers have cited abrasion, with circumstantial evidence indicating toothbrushing with a paste, as the main aetiological cause of dentin wear [70-72, 79, 103]. However, whilst radicular dentin wear from overzealous toothbrushing may be solely responsible for a small percentage of dentin hypersensitivity cases [104], it is likely that erosive components exacerbate the condition, resulting in tissue loss and tubular opening [105]. Today's low-abrasive toothpastes could minimise this risk if used in the normal twice-a-day manner [106].

Although the abrasivity of toothbrushing alone to enamel is almost certainly negligible, and minimal to dentin, features of the toothbrush head and filament stiffness can modify the abrasivity of toothpastes [107, 108] and force of brushing [109] in a normal twice-a-day brushing regimen in vitro studies $[95,103,105,110]$. In contrast, toothpaste has great potential to harm the dental hard tissues by virtue of its degree of abrasivity. The Relative Dentin Abrasion (RDA) and Relative Enamel Abrasion of a toothpaste define its abrasive potential on a normalised scale with an accepted standard material serving as a reference [111]. In situ studies to investigate the effects of abrasion on dentin have shown that dentin is considerably more susceptible than enamel to abrasion alone [112] and that significant differences in dentin wear can be detected between a moderate- and highRDA toothpaste [113]. These effects on enamel can be explained by the fact that most toothpaste contains abrasives which are softer than enamel. The exceptions are those few products containing non-hydrated alumina which can abrade enamel [88]. Even in these cases, careful extrapolation of data in vitro suggest, in normal use, that even these products would take hundreds of years to remove $1 \mathrm{~mm}$ of enamel. 
The susceptibility of dentin to abrasive wear has been shown to be further increased when challenged in vitro prior to toothbrushing with an erosive insult; the toothbrush easily removing the superficially demineralised hard tissue $[105,114]$, findings that were supported more recently in vitro [110] and in situ [106]. Both abrasive and erosive components are important in this type of tooth wear, and indeed the RDA of the paste may be more influential than the erosive component. This would suggest that for these individuals, a low or moderate RDA paste should be advocated for safety, as well as preventive advice on tooth wear.

When comparing manual brushes for types for bristle, soft and hard toothbrushes were found to produce no significant difference in toothbrush abrasion of softened human enamel [115]; the calculated thickness of the softened enamel varied between 254 and $323 \mathrm{~nm}$, depending on the acid used [116]. Reviews suggest that there is no difference in hard tooth tissue abrasion between electric or manual brushes using a toothpaste [80]. This is due to electric brushes using less force than manual brushes [80, 103]. An alternative explanation is that the rapid head and/or filament actions of electric brushes may quickly dislodge the toothpaste from the brush head [88].

Toothpaste detergents also chemically "abrade" dentin probably by dissolution of the collagen matrix [117]. However, in vitro data suggest that in normal use, toothpastes, conforming to the International Standards Organisation for abrasivity, will take many tens of years, in excess of one hundred years, to remove $1 \mathrm{~mm}$ of dentin $[118,119]$. Toothpastes therefore appear to play a role in localising sites of dentin hypersensitivity by acting synergistically with erosion in removing enamel at the cervical areas.

Erosion is defined as chemical wear as the result of extrinsic or intrinsic acid or chelators acting on plaque-free tooth surfaces [102]. Erosion starts by softening of the surface and is followed by continuous layer-by-layer dissolution leading to permanent loss of tooth volume with softened layer at the surface of the remaining tissue. There are extrinsic and intrinsic causes of erosion. Extrinsic factors are not only mainly acidic food and beverages but also medicines and oral hygiene products [120]. Intrinsic erosion is caused by gastric juices, possibly caused by, for example, reflux disease, eating disorders, chronic alcoholism and pregnancy. However, different biological, chemical and behavioural factors modify the effect of acidic agents on enamel [121]. In a hitherto unpublished study, the authors demonstrated that saliva, from patients without erosion, exhibited a protective effect compared to saliva from individuals with severe erosion. This may be one reason why some individuals exhibit less erosion than others even if they are exposed to exactly the same acid challenge in the diet. Erosive tooth wear is not caused solely by acid challenge and chelating agents themselves. In vitro studies show that a few micrometres of tissue is lost due to the influence of an erosive challenge (once the surface is softened, it might be easily abraded by oral soft tissues), toothbrushing with dentifrices or coarse food stuff $[120,122]$. Potential routes for deep acid penetration into the dentin are afforded by the dentin tubules where clearance and salivary buffering are less effective. The collagen layer is largely unaffected by dietary erosion and forms a mat of fibrils as the mineralized matrix dissolves, although abrasive influences will probably result in change. The relevance and clinical implications of this layer have yet to be fully understood in the erosion/abrasion wear of dentin [123, 124].

Erosion caused by extrinsic acids on hard tooth substrate has been considered to be the most common and important aetiological factor in tooth wear [125]. However, this may not be the case with cervical tooth wear seen in dentin hypersensitivity.

Abfraction (fatigue wear) means physical wear as a result tensile or shear stress in the cemento-enamel region provoking microfractures in enamel and dentin [102]. Many in vitro studies explaining cervical lesions as a result of abfraction do not consider the resilience of the periodontal ligament functioning as a shock absorber. Grippo and Simring [126] stated that toothpaste abrasion in a corrosive (erosive) environment increases loss of tooth structure due to tensile forces concentrated at the cervical area of teeth. It has also been postulated that lack of Hunter Schreger-bands in the vulnerable cervical region contributes to the development of abfraction lesions [127, 128]. Many teeth present signs of traumatic occlusion but do not show cervical lesions. Thus, occlusal trauma alone cannot satisfactorily explain the development of NCCLs, and it may be assumed that the role of occlusal loading in NCCLs appears to be part of a multifactorial event. A critical review [129] emphasised that the cause of pathological levels of tooth wear is difficult to diagnose and is generally a result of erosion, abrasion and attrition, and they also summarise that V-shaped lesion develop as a result of erosion and abrasion rather than from abfraction. Sharply defined margins could be caused by abfraction and/or abrasion due to excessive tooth brushing, while dish-shaped broader and shallow lesions could be caused by erosion. However, the term NCCL illustrates the fact that it is hardly possible to decide which kind of destruction leads to this kind of lesion.

Other types of wear affect hard tooth tissue; however, they are thought only rarely to be involved in the aetiology of dentin hypersensitivity. Foodstuffs are known to wear the occlusal surface of the teeth [114]; for example, the erosive nature of roasted vegetables compared to other cooking styles [130]. Attrition [131] may play a role in some cases of occlusal dentin hypersensitivity, due to parafunctional habits like bruxism [132]. 
Loss of dentin and enamel may be due to any or a combination of the tooth wear processes, including erosion, abrasion, attrition and abfraction. The interaction between erosion and abrasion would appear to be strong factors for the majority of wear at the cervical margin and opening of dentinal tubules.

\section{Lesion initiation}

\section{Abrasion and erosion}

To complete the scenario for dentin hypersensitivity to occur, the dentinal tubules need to be patent from the pulp to the oral environment [34] also evidenced by dentin with wider and more numerous tubules being more sensitive than nonsensitive dentin [33]. There is a continuous outflow of fluid from the open tubules [133]. If stimuli are then applied to the dentin, the rate of flow is increased, in turn exciting the nervous system [30] and resulting in a pain sensation.

The exposed dentin surface either has patent dentin tubules or is covered by a smear layer of oral debris such as calcium or toothpaste ingredients. Boyde et al. [134] first referred to the grinding debris on the surface of dentin as the "smear layer". The depth produced in the oral cavity is believed to range from 1 to $5 \mu \mathrm{m}$ according to Brännström [135], but is thought to be up to $10-15 \mu \mathrm{m}$ in vitro [136]. Many investigators have established that the smear layer is acid-labile [105, 137]. Most acidic soft drinks, citrus fruits and fruit juices, some alcoholic beverages and many herbal teas remove the smear layer $[105,138]$ after a few minutes of exposure. Further, these acids can dramatically reduce the dentin surfaces' ability to resist abrasive forces due to surface softening $[10,105,139,140]$ resulting in further dentin removal and wider open dentin tubules. Contrary to popular belief, yoghurts were not found to cause erosion of enamel and remove the smear layer [141]. Some mouthrinses with low $\mathrm{pH}$ will readily dissolve the smear layer to expose open tubules [142] as do some toothpastes detergents, such as sodium lauryl sulphate [143, 144]. Most mechanical influences on dentin, for example, abrasion and attrition, cause a plastic tissue flow and produce or remove a smear layer [145]. Although toothbrushing per se can open and close dentin tubules, as demonstrated by Absi et al. [105], this takes in excess of 24-h continual brushing with water and after a few hours with toothpaste brushing. Brushing with an occluding toothpaste can occlude tubules [146-149] with deposition of toothpaste ingredients on dentin and in tubule orifices. However, non-occluding toothpastes may open tubules due to their abrasive nature $[144,150,151]$. A systematic review conducted by von Troil et al. [59] looked at the prevalence of root sensitivity following periodontal therapy, concluding that root sensitivity occurs in approximately half of the patients following subgingival scaling and root planing due to opening and closing of the tubules, respectively.

In conclusion, lesion initiation in dentin hypersensitivity can be induced by abrasive and erosion forces. Although erosion is the dominant factor, synergistic action with abrasion is probably the most common occurrence; these factors result in tubule opening and dentin wear.

\section{Plaque}

The formation of bacterial plaque on exposed dentin surfaces has potential to induce pathological change in the pulpal tissue down to patent dentin tubules due to diffusion of bacterial products and substances release by inflammatory processes. Adriaens [152] first published work in this field, but more recently, Love et al. [153] has shown that bacterial invasion of dentinal tubules commonly occurs when dentin is exposed following a breach in the integrity of the overlying enamel or cementum, with bacterial products able to evoke inflammatory changes in the pulpodentin complex. However, there is no link to dentin hypersensitivity yet.

\section{Bleaching}

Tooth sensitivity following vital tooth bleaching is a cause for concern, affecting most people and lasting for 1-4 days on average [154]. Sensitivity is thought to be due to the hydrogen peroxide molecules passing through the enamel and dentin into the pulp and causing pulpal inflammation [155], which is different from the aetiology of dentin hypersensitivity. Sensitivity from bleaching is usually transient, although if bleaching is performed on individuals already exhibiting sensitive dentin, the sensitivity can be severe and prolonged. Desiccation of the tooth surface may also play a role influencing sensitivity from vital bleaching [36].

\section{Susceptibility and risk factors}

Individuals will respond differently to the same risk factors influencing outcome, while other individuals will subject themselves to a particular risk factor far more often than average. When 10 volunteers imbibed 11 of a soft acidic drink over a period of 15 days, some volunteers showed minimal erosion of enamel and others far more erosion [156]. Identification of the cause of susceptibility is unknown but likely to be due to salivary buffering and flow rate [157], pellicle thickness and charge [158], movements of the soft tissues [159], distribution and time of acidic liquid in the oral cavity [160], tooth structure [139] and remineralising potential [161, 162]. Difference in saliva flow and composition could contribute to the development 
of hypersensitivity by affecting the surface layer or deposition of intratubular dentin [163]. Similarly, the biotype of the gingival margin [85], oral hygiene habits such as excessive toothbrushing and consumption of copious acidic beverage often accompanied with toothbrushing soon after consumption, will predispose the individual to dentin hypersensitivity [10].

Similar to periodontal disease and many other medical conditions, there needs to be a susceptible individual who is exposed to a one or more risk factors for dentin hypersensitivity to occur.

Conflict of interest The authors declare that they have no conflict of interest.

\section{References}

1. Foressell-Ahlberg K, Brännström M, Edwall L (1975) The diameter and number of dentinal tubules in rat, cat, dog and monkey. Acta Odontol Scan 33:243-250

2. Garberoglio R, Brännström M (1976) Scanning electron microscopic investigation of human dentinal tubules. Arch Oral Biol $21: 355-362$

3. Matthews B, Hughes SHS (1988) The ultrasonic and receptor transduction mechanisms of dentine. In: Iggo A, Hamman W (eds) Progress in brain research. Elsevier, Amsterdam, pp 69-76

4. Byers MR (1984) Dental sensory receptors. International Rev Neurobiol 5:39-41

5. Mumford JM (1982) Orofacial pain. Aetiology, diagnosis and treatment, 3rd edn. Churchill Livingstone, Philadelphia, pp $152-179$

6. Nähri M, Jyväsjärvi E, Virtannen A (1992) Role of intradental Aand $\mathrm{C}$ - type fibres in dental pain mechanisms. Proc Finn Dent Soc 88(Suppl 1):507-516

7. Matthews B, Andrew D, Wanachantararak S (2000) Biology of the dental pulp with special reference to its vasculature and innervation. In: Embery G, Edgar WM, Orchardson R, Addy M (eds) Tooth wear and sensitivity. Taylor and Francis, London, pp 39-51

8. Nuttall NM (2001) A guide to the UK adult dental health survey 1998. British Dental Association; London, pp 1-7; 35; 47-55

9. Steele J, O' Sullivan I (2011) Executive summary: adult dental health survey 2009. The Health and Social Care Information Centre, NHS National Statistics. http://www.dhsspsni.gov.uk/ adhexecutivesummary.pdf. Accessed 03 October 2012

10. Addy M (2002) Dentine hypersensitivity: new perspectives on an old problem. Int Dent J 52(Suppl):367-375

11. Addy M, Mostafa P, Newcombe RG (1987) Dentine hypersensitivity: the distribution of recession, sensitivity and plaque. J Dent $15: 242-248$

12. Blum M (1530) German anonymous. Artzney buch wider Allerbi. Krancheyton und Gebrechen der Tzeen

13. Addy M, Dowell P (1983) Dentine hypersensitivity-a review: clinical and in vitro evaluation of treatment agents. J Clin Periodont 10:351-363

14. Merskey H (1979) Pain terms: a list with definitions and notes on usage - recommended by the IASP Subcommittee on taxonomy. Pain 6:249-252

15. Sosnow I (1962) The emotional significance of the loss of teeth. In: Barland LR, Vintan PW (eds) Dental clinics of North
America, symposium on psychology in dentistry II. Removable Partial Dentures Saunders, Philadelphia, pp 637-650

16. Trowbridge HO (1985) Mechanism of pain induction in hypersensitive teeth. In: Rowe NH (ed) Proceedings of symposium on hypersensitive dentine origin and management. University of Michigan, School of Dentistry, Ann Arbor, pp 1-6

17. Seltzer S, Bender IB, Ziantz M (1963) The dynamics of pulp inflammation: correlation between diagnostic data and actual histological findings in the pulp. Oral Surg, Oral Med, Oral Pathol 16:846-969

18. Tydesley WR, Mumford JM (1970) Dental pain and the histological condition of the pulp. Dent Practit 20:333-336

19. Rapp R, Avery JK, Recoter RA (1957) A study of the distribution of nerves in human teeth. J Canad Dent Assoc 23:447-453

20. Frank RM, Steuer P (1988) Transmission electron microscopy of the human odontoblast process in peripheral root dentine. Arch Oral Biol 33:91-98

21. Rapp R, Avery JK, Strachen DS (1968) Possible role of the aceylcholinesterase in neural conduction within the dental pulp. In: Finn SB (ed) Biology of dental pulp organ. University of Alabama Press, Birmingham, p 309

22. Närhi MVO (1985) Dentine sensitivity: a review. J Biol Buccale 13:75-96

23. Frank RM (1968) Ultrastructural relationship between the odontoblast, its process and the nerve fibre. In: Symons NBB (ed) Dentine and pulp: their structure and reactions: a symposium at the Dental School, University of Dundee, September, 1967. University of Dundee, Dundee, pp 115-145

24. Närhi MVO (1990) The neurophysiology of the teeth. Dent Clin North Am 34:439-448

25. Hirvonen TJ, Närhi MVO, Hakumaki MOK (1984) The excitability of dog pulp nerves in relation to the condition of dentine surface. J Endod 10:294-298

26. Berkovitz BKB, Holland GR, Moxham BJ (1981) A colour atlas and textbook of oral anatomy, 4 th edn. Wolfe Medical Publications Ltd, London, pp 78-110

27. Gysi A (1900) An attempt to explain the sensitiveness of dentin. Br J Dent Sci 43:865-868

28. Brännström M (1963) A hydrodynamic mechanism in the transmission of pain-produced stimuli through the dentine. In: Anderson DJ (ed) Sensory mechanisms in dentine. Pergamon, Oxford, pp 73-79

29. Brännström M (1965) The surface of sensitive dentine. Odontol Revy 16:293-299

30. Brännström M (1966) The sensitivity of dentine. Oral Surg, Oral Med, Oral Path 21:517-526

31. Fogel HM, Marshall FJ, Pashley DH (1988) Effects of distance from the pulp and thickness on the hydraulic conductance of human radicular dentine. J Dent Res 67:1381-1385

32. Nähri M, Kontturi-Nähri V (1994) Sensitivity and surface condition of dentine - an SEM replica study. J Dent Res 73:122

33. Absi EG, Addy M, Adams D (1987) Dentine hypersensitivity: a study of the patency of dentinal tubules in sensitive and nonsensitive cervical dentine. J Clin Periodont 14:280-284

34. Absi EG, Addy M, Adams D (1989) Dentine hypersensitivity: the development and evaluation of a replica technique to study sensitive and nonsensitive cervical dentine. J Clin Periodont 16:190-195

35. Guyton A (1971) Textbook of medical physiology, 4th edn. W B Saunders, Philadelphia, pp 211-212

36. Matthews B, Vongsavan N (1994) Interactions between neural and hydrodynamic mechanism in dentine and pulp. Arch Oral Biol 39:87-95

37. Pashley DH (1990) Mechanisms of dentine sensitivity. Dent Clin North Am 34:449-474

38. Kleinberg I, Kaufdentman HW, Confessore F (1990) Methods of measuring tooth hypersensitivity. Dent Clin North Am 34:515-530 
39. Mumford JM, Newton AV (1969) Transduction of hydrostatic pressure to electrical potential in human dentine. J Dent Res 53:226-229

40. Griffiths H, Morgan G, Williams K, Addy M (1993) The measurement in vitro of streaming potentials with fluids flow across dentine and hydroxyapatite. J Periodont Res 28:59-65

41. Magloire H, Maurin JC, Couble ML, Shibukawa Y, Tsumura M, Thivichon-Prince B, Bleicher F (2010) Topical review. Dental pain and odontoblasts: facts and hypotheses. J Orofac Pain $24: 335-349$

42. Chen S, Rio C, Ji RR (2003) Disruption of ErbB receptor signalling in adult non-myelinating Schwann cell causes progressive sensory loss. Nat Neurosci 6:1186-1193

43. Sanz M, Addy M (2002) Group D summary. J Clin Periodont 29 (Supplement 3):195-196

44. Scott JH, Symons NBB (1982) Introduction to dental anatomy, 9th edn. Churchill Livingstone, Philadelphia, pp 235-247

45. Couvre E (1986) Ultrastructural changes during the life cycle of human odontoblasts. Arch Oral Biol 31:643-651

46. Walton RE, Outhwaite WC, Pashley DH (1976) Magnification, an interesting optical property of dentine. J Dent Res 55:639-642

47. Fosse G, Saele PK, Eide R (1992) Numerical dentistry and distribution pattern of dentine tubules. Acta Odontol Scand 50:201-210

48. Pashely D (1996) Dynamics of the pulp-dentinal complex. Cri rev Oral Bio Med 7:104-133

49. Anderson DJ, Hannam AG, Matthews B (1972) Sensory mechanisms in mammalian teeth and their supporting structures. Physiol Rev 59:171-195

50. Smith A, Sloan A, Matthews J, Murray P, Lumley P (2000) Reparative processes in dentine and pulp. In: Addy M, Embery G, Edgar WM, Orchardson R (eds) Tooth wear and sensitivity. Taylor and Francis, London, pp 54-66

51. Bevenius J, Lindskog S, Hultenby K (1994) The micromorphology in vivo of the buccocervical region of premolar teeth in young adults. A replica study by scanning electron microscopy. Acta Odontol Scand 52:323-334

52. Susin C, Haas AN, Oppermann RV, Haugejorden O, Albandar JM (2004) Gingival recession: epidemiology and risk indicators in a representative urban Brazilian population. J Periodontol $75: 1377-1386$

53. Smith RG (1997) Gingival recession. Reappraisal of an enigmatic condition and a new index for monitoring. $\mathrm{J}$ Clin Periodont 24:201-205

54. Gorman WJ (1967) Prevalence and etiology of gingival recession. J Periodont 38:316-322

55. Watson PJC (1984) Gingival recession. J Dent 12:29-35

56. Tugnait A, Clerehugh V (2001) Gingival recession-its significance and management. J Dent 29:381-394

57. Löe H, Ånerud Å, Boysen H (1992) The natural history or periodontal disease in man: prevalence, severity and extent of gingival recession. J Periodont 63:489-495

58. Serino G, Wennström J, Lindhe J, Eneroth L (1994) The prevalence and distribution of gingival recession in subjects with high standards of oral hygiene. J Clin Periodont 21:57-63

59. Von Troil B, Needleman I, Sanz M (2002) A systematic review of the prevalence of root sensitivity following periodontal therapy. $\mathrm{J}$ Clin Periodontol 29:173-177

60. Van deer Valdes U (1982) Regeneration of the interdentally soft tissues following denudation procedures. J Clin Periodontol 9:455-459

61. Lang N, Bräggeer U, Tonetti M, Hämmerle C (1998) Supportive periodontal therapy (STP). In: Lindhe J (ed) Clinical periodontology and implant dentistry, 3rd edn. John Wiley \& Sons, Hoboken, pp 822-864
62. Wennström J, Serino G, Lindhe J, Eneroth L, Tollsko Q (1993) Periodontal condition of adult regular dental attendants: a 12 year longitudinal study. J Clin Periodontol 20:714-722

63. Calsina G, Ramón JM, Echeverría JJ (2002) Effects of smoking on periodontal tissues. J Clin Periodontol 29:771-776

64. Baumert Ah M, Johnson G, Kaldahl W, Patil K, Kalkwart K (1994) The effect of smoking on the response to periodontal therapy. J Clin Periodontol 21:91-97

65. Trombelli L, Scabbia A (2005) Healing response of gingival recession defects following guided tissue regeneration procedures in smokers and non-smokers. J Clin Periodontol 24:529-533

66. Chambrone L, Lima LA, Pustiglioni FE, Chambrone LA (2009) Systematic review of periodontal plastic surgery in the treatment of multiple recession-type defects. J Can Dent Assoc 75:203a$203 \mathrm{f}$

67. Gunsolley JC, Quinn SM, Tew J, Gooss CM, Brooks CN, Schenkein HA (1998) The effect of smoking on individuals with minimal periodontal destruction. J Periodontol 69:165-170

68. Müller HP, Stadermann S, Heinecke A (2002) Gingival recession in smokers and non-smokers with minimal periodontal disease. J Clin Periodontol 29:129-136

69. Davis WB (1978) The cleansing, polishing and abrasion of teeth and dental products. Cosmet Sci 1:39-81

70. Kitchin P (1941) The prevalence of tooth root exposure and the relation of the extent of such exposure to the degree of abrasion in different age classes. J Dent Res 20:565-581

71. Gillette WB, Van House RL (1980) Ill effects of improper oral hygiene procedures. J Am Dent Assoc 10:476-481

72. Hirschfeld I (1939) The toothbrush: its use and abuse. In: Kimpton (ed) Dental items of interest. Dental Items of Interest Publishing Co, Boston pp 1-27, 262-267, 358-465, 484-495

73. Khoory T (1983) The use of chewing sticks in preventive oral hygiene. Clin Prevent Dent 4:11-14

74. Slots J (2003) Update on general health risk of periodontal disease. Int Dent J 53:200-207

75. Rugg-Gunn AJ, MacGregor IDM (1978) A survey of toothbrushing behaviour in children and young adults. J Periodontol Res $13: 382-388$

76. MacGregor IDM, Rugg-Gunn A-J (1979) A survey of toothbrushing sequence in children and young adults. J Periodont Res 14:225-230

77. Robinson PG, Deacon SA, Deery C, Heanue M, Walmsley AD, Worthington HV, Glenny A-M, Shaw BC (2005) Manual versus powered toothbrushing for oral health. The Cochrane Collaboration, Wiley, Hoboken, Cochrane Review

78. Addy M, Dummer P, Hunter M, Kingdon A, Shaw W (1988) Changes in the prevalence of plaque, gingivitis and pocketing in a group of South Wales schoolchildren examined at the ages of 1112 years and 15-16 years. Comm Dent Health 5:345-354

79. Addy M, Hunter ML (2003) Can toothbrushing damage your health? Effects on oral and dental tissues. Int Dent J 53:177-186

80. Van der Weijden GA, Timmerman MF, Reijerse E, Snoek CM (1996) Toothbrushing force in relation to plaque removal. J Clin Periodontol 23:724-729

81. Knocht A, Simon G, Person P, Denepitiya JL (1993) Gingival recession in relation to history of hard toothbrush use. J Periodontol 64:900-905

82. West N (1985) Dentine hypersensitivity: clinical and laboratory studies of toothpastes and their ingredients $\mathrm{PhD}$ Thesis, University of Wales College of Medicine

83. Gillam DG, Seo HS, Bulman JS, Newman HN (1999) Perceptions of dentine hypersensitivity in a general practice population. Journal of Oral Rehabilitation 26:710-714

84. Gillam DG, Bulman JS, Eijkman MA, Newman HN (2002) Dentists' perceptions of dentine hypersensitivity and knowledge of its treatment. J Oral Rehab 29:219-225 
85. Buser D, Belser U, Wismeijer D (2000) The treatment guide ITI. vol 1. Quintessence Publishing Co, Ltd, London

86. De Rouck T, Eghbali R, Collys K, De Bruyn H, Cosyn J (2009) The gingival biotype revisited: transparency of the periodontal probe through the gingival margin as a method to discriminate thin from thick gingiva. J Clin Periodontol 36(5):428-433

87. Melsen B, Allais D (2005) Factors of importance for the development of dehiscences during labial movement of mandibular incisors: a retrospective study of adult orthodontic patients. Am J Orthod and Dentofacial Orthopaed 127:552-556

88. Addy M (2008) Oral hygiene products: potential for harm to oral and systemic health? Periodontology 2000(48):54-65

89. Lost C (1984) Depth of alveolar bone dehiscences in relation to gingival recession. J Clin Periodontol 11:583-589

90. Jeger F, Lussi A, Zimmerli B (2009) Oral jewelry: a review. Schweiz Monatsschr Zahnmed 119:615-631

91. Levin L, Zadik Y (2007) Oral piercing: complications and side effects. Am J Dent 20:340-344

92. Slutzkey S, Levin L (2008) Gingival recession in young adults: occurrence, severity, and relationship to past orthodontic treatment and oral piercing. Am J Orthod Dentofacial Orthop 134:652-656

93. Abboud M, Gruner M, Koeck B (2002) Anterior crowding - just an esthetic problem? J Orofac Orthop 63:264-273

94. Joss-Vassalli I, Grebenstein C, Topouzelis N, Sculean A, Katsaros C (2010) Orthodontic therapy and gingival recession: a systematic review. Orthod Craniofac Res 13:127-141

95. Mair LH (2000) Wear in the mouth: the tribology dimension. In: Addy M, Embery G, Edgar WM, Orchardson R (eds) Tooth wear and sensitivity: clinical advances in restorative dentistry. Taylor and Francis, London, pp 181-188

96. Meurman JH, Sovari R (2000) Interplay of erosion, attrition and abrasion in toothwear and possible approaches to prevention. In: Addy M, Embery G, Edgar WM, Orchardson R (eds) Tooth wear and sensitivity: clinical advances in restorative dentistry. Taylor and Francis, London, pp 171-180

97. Kaidonis JA (2008) Tooth wear: the view of the anthropologist. Clin Oral Investig 12:S21-S26

98. Aubry M, Mafart B, Donat B, Brau JJ (2003) Brief communication: study of noncarious cervical tooth lesions in samples of prehistoric, historic, and modern populations from the South of France. Am J Phys Anthropol 121:10-14

99. Falin LI (1961) Histological and histochemical studies of human teeth of the bronze and stone ages. Arch Oral Biol 5:5-13

100. Lussi A, Hellwig E (2006) Risk assessment and preventive measures. In: Lussi A (ed) Dental erosion: from diagnosis to therapy. Monogr. Oral Sci, Karger, Basel 20, pp 190-199

101. Wood ID, Kassir AS, Brunton PA (2009) Effect of lateral excursive movements on the progression of abfraction lesions. Oper Dent 34:273-279

102. Ganss C (2006) Definition of erosion and links to tooth wear. In: Lussi A (ed) Dental erosion: from diagnosis to therapy. Monogr. Oral Sci, Karger, Basel 20: pp 9-16

103. Phaneuf EA, Harrington JH, Dale PP, Shklar G (1962) Automatic toothbrush: a new reciprocating action. J Am Dent Assoc 65:12-25

104. Addy M (2005) Tooth brushing, tooth wear and dentine hypersensitivity - are they associated. Inter Dent J 55:261-267

105. Absi EG, Addy M, Adams D (1992) Dentine hypersensitivity. The effects of toothbrushing and dietary compounds on dentine in vitro: a SEM study. J Oral Rehab 19:101-110

106. West N, Hooper S, O'Sullivan D, Hughes N, North M, Macdonald E, Davies M, Claydon N (2012) In situ randomised trial investigating abrasive effects of two desensitising toothpastes on dentine with acidic challenge prior to brushing. J Dent 40:77-85
107. Dyer D, Addy M, Newcombe RG (2000) Studies in vitro of abrasion by different manual toothbrush heads and a standard toothpaste. J Clin Periodont 27:99-103

108. Wiegand A, Egert S, Attin T (2008) Toothbrushing before or after an acidic challenge to minimize tooth wear? An in situ/ex vivo study. Am J Dent 21:13-16

109. Wiegand A, Köwing L, Attin T (2007) Impact of brushing force on abrasion of acid-softened and sound enamel. Arch Oral Biol 52:1043-1047

110. Wiegand A, Kuhn M, Sener B, Roos M, Attin T (2009) Abrasion of eroded dentin caused by toothpaste slurries of different abrasivity and toothbrushes of different filament diameter. J Dent $37: 480-484$

111. Hefferren JJ (1976) A laboratory method for assessment of dentifrice abrasivity. J Dent Res 55:563-573

112. Hooper S, West NX, Pickles M, Joiner A, Newcombe RG, Addy M (2003) Investigation of erosion and abrasion of enamel and dentine: a model in situ using toothpastes of different abrasivity. $\mathrm{J}$ Clin Periodont 30:802-808

113. Addy M, Hughes J, Pickles M, Joiner A, Huntington E (2002) Development of a method in situ to study toothpaste abrasion of dentine: comparison of 2 products. J Clin Periodont 29:896-900

114. Davis WB, Winter PJ (1980) The effect of abrasion on enamel and dentine after exposure to dietary acid. Br Dent J148:253-256

115. Voronets J, Jaeggi T, Buergin W (2008) Lussi A controlled toothbrush abrasion of softened human enamel. Caries Res 42:286-290

116. Voronets J, Lussi A (2012) Thickness of softened human enamel removed by toothbrush abrasion: an in vitro study. Clin Oral Investig 14:251-256

117. Moore C, Addy M (2005) Wear of dentine in vitro by toothpaste abrasive and detergents alone and combined. J Clin Periodontol 32:1242-1246

118. Addy M, Griffiths G, Dummer P, Kingdom A, Shaw WC (1987) The distribution of plaque and gingivitis and the influence of brushing hand in a group of 11-12 year old school children. J Clin Periodontol 14:564-572

119. Hunter ML, Addy M, Pickles MJ, Joiner A (2002) The role of toothpastes and toothbrushes in the aetiology of toothwear. Int Dent J 52:399-405

120. Lussi A, Jaeggi T (2008) Erosion-diagnosis and risk factors. Clin Oral Investig 12:5-13

121. Lussi A (2006) Erosive tooth wear-a multifactorial condition of growing concern and increasing knowledge. In: Lussi A (ed) Dental erosion: from diagnosis to therapy. Monogr Oral Sci, Karger, Basel 20:1-8

122. Addy M, Pearce N (1994) Aetiological, predisposing and environmental factors in dentine hypersensitivity. Arch Oral Biol 39:33-38

123. Shellis RP, Barbour ME, Jones SB, Addy M (2010) Effects of pH and acid concentration on erosive dissolution of enamel, dentine and compressed hydroxyapatite. Eur J Oral Sci 118:475-482

124. De Menezes M, Turssi CP, Hara AT, Messias DC, Serra MC (2004) Abrasion of eroded root dentine brushed with different toothpastes. Clin Oral Invest 8:151-155

125. Bartlett DW (1997) The causes of dental erosion. Oral Diseases 3:209-211

126. Grippo JO (1991) Abfractions: a new classification of hard tissue lesions of teeth. J Esthetic Dent 3:14-19

127. Lynch CD, O’Sullivan VR, Dockery P, McGillycuddy CT, Rees JS, Sloan AJ (2011) Hunter-Schreger band patterns and their implications for clinical dentistry. J Oral Rehabil 38:359-365

128. Pegoraro LF, Scolaro JM, Conti PC, Telles D, Pegoraro TA (2005) Noncarious cervical lesions in adults: prevalence and occlusal aspects. J Am Dent Assoc 136:1694-1700 
129. Bartlett DW, Shah P (2006) A critical review of non-carious cervical (wear) lesions and the role of abfraction, erosion, and abrasion. J Dent Res 85:306-312

130. Chadwick RG (2006) The effect of cooking method upon the titratable acidity of a popular vegetarian dish - scope for reducing its erosive potential? Eur J Prosthodont Restor Dent 14:28-31

131. Bartlett D, Smith BGN (2000) Definition, classification and clinical assessment of attrition, erosion and abrasion of enamel and dentine. In: Addy M, Embery G, Edgar WM, Orchardson R (eds) Tooth wear and sensitivity: clinical advances in restorative dentistry. Taylor and Francis, London, pp 87-92

132. Ekfeldt A, Hugoson A, Bergendal T (1990) An individual tooth wear index and an analysis of factors correlated to incisal and occlusal wear in an adult Swedish population. Acta Odontol Scand 48:343-349

133. Vongsavan N, Matthews B (1992) Fluid flow through dentine in vivo. Arch Oral Biol 37:175-185

134. Boyde A, Switsur VR, Stewart ADG (1963) An assessment of two new physical methods applied to the study of dental tissues. In: Hardwick JL (ed) Advances in fluorine research and dental caries prevention, 1st edn. Pergamon, Oxford, pp 185-193

135. Brännström M (1982) In: Dentine and pulp in restorative dentistry. Wolfe Medical Publication Ltd

136. Pashley DH (1984) Smear layer physiological considerations. Oper Dent Suppl 3:13-29

137. Pashley DH (1979) The influence of dentine permeability and pulpal blood flow on pulpal solute concentrations. J Endod 5:355-361

138. Phelan J, Rees J (2002) The erosive potential of some herbal teas. J Dent 31:241-246

139. Vanuspong W, Eisenburger M, Addy M (2002) Cervical tooth wear and sensitivity: erosion, softening and rehardening of dentine: effects of $\mathrm{pH}$, time and ultrasonication. J Clin Periodontol 29:351-357

140. Eisenburger M, Hughes J, West NX, Jandt KD, Addy M (2004) Ultrasonication as a method to study enamel demineralisation during acid erosion. Caries Res 34:289-294

141. Lussi A, Megert B, Shellis RP, Wang X (2012) Analysis of the erosive effect of different dietary substances and medications. $\mathrm{Br}$ J Nutr 107:252-262

142. Pontefract H, Hughes J, Kemp K, Yates R, Newcombe RG, Addy M (2001) Erosive effects of some mouthrinses on enamel. A study in situ. J Clin Periodontol 28:319-324

143. Parkinson CR (2007) Smear layer integrity and the role of surfactants. J Dent Res 86(Spec Iss B):188, PEF (www.dentalresearch.org)

144. West NX, Hughes J, Addy M (1998) Dentine hypersensitivity: the effects of brushing desensitising toothpastes, their solid and liquid phases and detergents on dentine and acrylic. Studies in vitro. J Oral Rehab 25:885-895

145. Shortall AC (1981) Cavity cleaners in restorative dentistry. $\mathrm{Br}$ Dent J 150:243-247

146. Petrou I, Heu R, Stranick M, Lavender S, Zaidel L, Cummins D, Sullivan RJ, Hsueh C, Gimzewski JK (2009) A breakthrough therapy for dentin hypersensitivity: how dental products containing $8 \%$ arginine and calcium carbonate work to deliver effective relief of sensitive teeth. J Clin Dent 20:23-31

147. Mason S, Hughes N, Sufi F, Bannon L, Maggio B, North M, Holt J (2010) A comparative clinical study investigating the efficacy of a dentifrice containing $8 \%$ strontium acetate and $1040 \mathrm{ppm}$ fluoride in a silica base and a control dentifrice containing $1450 \mathrm{ppm}$ fluoride in a silica base to provide immediate relief of dentine hypersensitivity. J Clin Dent 21:42-48

148. Hughes N, Mason S, Jeffery P, Welton H, Tobin M, O'Shea C, Browne MA (2010) Comparative clinical study investigating the efficacy of a test dentifrice containing $8 \%$ strontium acetate and $1040 \mathrm{ppm}$ sodium fluoride versus a marketed control dentifrice containing $8 \%$ arginine, calcium carbonate, and $1450 \mathrm{ppm}$ sodium monofluorophosphate in reducing dentinal hypersensitivity. J Clin Dent 21:49-55

149. Ayad F, Ayad N, Delgado E, Zhang YP, DeVizio W, Cummins D, Mateo LR (2009) Comparing the efficacy in providing instant relief of dentin hypersensitivity of a new toothpaste containing $8.0 \%$ arginine, calcium carbonate, and $1450 \mathrm{ppm}$ fluoride to a benchmark desensitizing toothpaste containing $2 \%$ potassium ion and $1450 \mathrm{ppm}$ fluoride, and to a control toothpaste with $1450 \mathrm{ppm}$ fluoride: a three-day clinical study in Mississauga, Canada. J Clin Dent 20:115-122

150. Pashley DH, Galloway SE (1985) The effects of oxalate treatment on the smear layer of ground surfaces of human dentine. Arch Oral Biol 30:731-737

151. Addy M, Mostafa P (1989) Dentine hypersensitivity 11. Effects produced by the uptake in vitro of toothpastes onto dentine. J Oral Rehab 16:35-48

152. Adrians PA, De Boever JA, Loesche WS (1988) Bacterial invasion in rat cementum and radicular dentine of periodontally diseased teeth in humans. A reservoir of periodontopathic bacteria. J Periodont 59:222-229

153. Love RM, Jenkinson HF (2002) Invasion of dentinal tubules by oral bacteria. Crit Rev Oral Biol Med 13:171-183

154. Van Haywood B (2002) Dentine hypersensitivity: bleaching and restorative considerations for successful management. Inter Dent J 52:7-10

155. Haywood VB (1992) History, safety and effectiveness of current bleaching techniques and application of night guard vital bleaching techniques. Quint Inter 27:471-488

156. West NX, Maxwell A, Addy M, Parker D, Jackson RJ (1998) A method to measure clinical erosion. The effect of orange juice consumption on erosion of enamel J Dent 4:329-335

157. Larson MJ, Pearce EI (2003) Saturation of human saliva with respect of calcium salts. Arch Oral Biol 48:317-322

158. Hannig C, Hannig M, Attin T (2005) Enzymes in the acquired enamel pellicle. Eur J Oral Sci 113:2-13

159. Gregg T, Mace S, West NX, Addy M (2004) A study in vitro of the abrasive effect of the tongue on enamel and dentine softened by acid erosion. Caries Res.38:557-560

160. Hara A, Lussi A, Zero D (2006) Biological factors. In: Lussi A (ed) Dental erosion: from diagnosis to therapy Monogr Oral Sci, Karger, Basel 20: pp 88-99

161. Eisenberger M, Addy M, Hughes J, Shellis P (2000) Effect of time on the remineralisation of enamel by synthetic saliva after citric acid erosion. Caries Res 35:211-215

162. Fushida CE, Cury JA (1999) Evaluation of enamel-dentine erosion by beverage and recovery by saliva and fluoride. J Dent Res 78:410

163. Orchardson R (2000) Strategies for the management of dentine hypersensitivity. In: Addy M, Embery G, Edgar WM, Orchardson $\mathrm{R}$ (eds) Tooth wear and sensitivity. Taylor and Francis, London, pp 315-325 